\title{
Celebrating remarkable vision
}

$T_{1}$ he António Champalimaud Vision Award was established by the Champalimaud Foundation to honor major contributions to vision research and organizations that work toward the global alleviation of vision problems. In June, the foundation recognized two American scientists for their contributions to visual neuroscience, J. Anthony Movshon, director of the Center for Neural Science at New York University, and William T. Newsome, a Howard Hughes Medical Institute investigator and professor at Stanford University (Figure 1).

JCI: The Champalimaud Vision Award celebrates your individual and collaborative accomplishments. What do you think is the most important discovery you've made together?

Movshon: The first work Bill and I did together (with Ted Adelson and Martin Gizzi) cracked open a particularly tough problem in neural computation, often called the "aperture problem." This problem occurs because each neuron "sees" only a small piece of the visual image, but it is necessary to integrate information from many pieces of the image to determine such

apparently simple things as the overall form or motion of an object. Bill and I uncovered the basic framework that the brain uses to solve this problem, though proving that we had it right took another 20 years.

Newsome: A long-standing and important question in vision science is how the electrical activity of neurons in the visual cortex relates to what we see. When Tony and I began collaborating, the question had been addressed in very limited ways, usually involving a comparison of electrophysiological recordings from animals to perceptual measurements from human subjects. Our innovation was to measure both electrophysiological signals and perceptual data from the same animal (rhesus monkeys), at the same time, under identical conditions. What we found was pretty amazing - that many neurons in the motion pathway were just as sensitive to the directional information in the visual stimulus as was the monkey perceptually. This finding sort of turned the fundamental problem on its head; we were forced to ask why perceptual
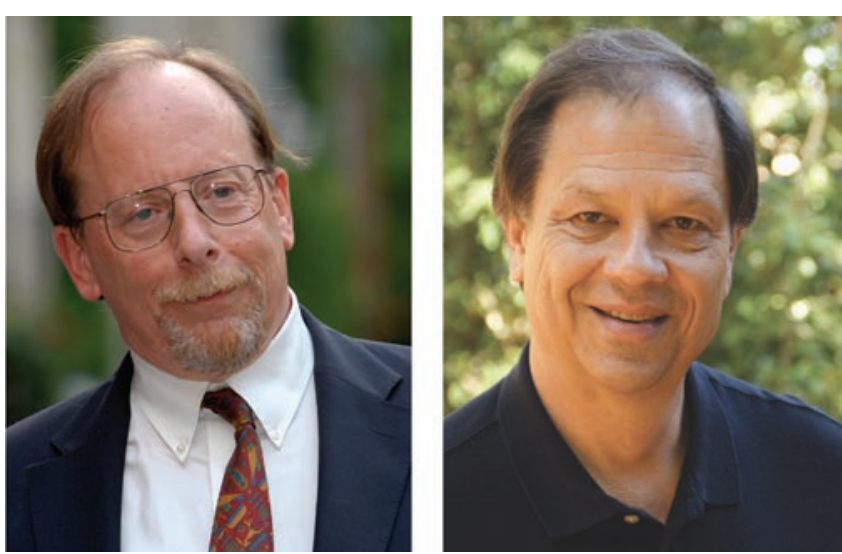

Figure 1

J. Anthony Movshon (left) and William T. Newsome. performance seemed rather limited when single cells in the visual cortex were so incredibly sensitive to the motion information.

JCI: How will your work translate into discoveries that will affect human health?

Newsome: First, our work may translate into the development of prosthetic devices that eventually restore some limited vision to people who are blind due to injury or diseases of the eye. Second, I think we can look forward to increasingly rich interactions between scientists studying biological ing. That was only the first of many epic debates that we have had over the years.

JCI: How do you address difficulties in collaboration while working on opposite sides of the country?

Movshon: It's really no big deal. There is something liberating about leaving your regular lab environment and camping out in someone else's - any problem that comes up belongs to someone else, and when the phone rings, it is never for you. And because you're a guest, people who might otherwise ignore you feel obliged to pay attention. My visits to Bill were among the most concentrated and productive periods I have experienced.

JCI: How has the field of cognitive neuroscience changed since you started your careers?

Movshon: Cognitive neuroscience as a discipline really didn't exist when I took my first academic position. I was a "physiological psychologist," and I had the good fortune to be well trained during my doctoral work in both neurophysiology and psychophysics. The fusion of biological and behavioral measures of mental function is a cornerstone of cognitive neuroscience.

Newsome: Now, knowledge vision and those studying artificial vision. Building better artificial visual systems will enhance many areas of human endeavor, from industrial applications to scientific applications to assisting visually impaired humans in their everyday lives.

JCI: How did you two meet?

Newsome: I doubt that he actually remembers the encounter, but Tony and I first met on an elevator in a hotel at the annual Association for Research in Vision and Ophthalmology meeting when I was a graduate student in 1978 or so. I had just given my very first scientific talk at a professional meeting, and Tony recognized me on the elevator and went out of his way to tell me what a nice talk I had given.

Movshon: Despite his claims to the contrary, I do remember his first talk, and our first meeting. I also remember something he neglected to tell you: the three-hour knockdown, drag-out dinner table argument that preceded our decision to begin collaborat- of the visual cortex is taken for granted, and we use the visual system as a platform to ask sophisticated questions about how cognitive functions such as perception, decision making, attention, memory, and planning actually work. Such topics were the province of psychology in the 1970s, not neurobiology, and neurobiologists who seriously entertained thoughts of studying such cognitive phenomena mechanistically were considered to be "fringe" characters!

JCI: This award is sometimes referred to as the "Nobel Prize for Vision Research." Is a trip to Stockholm next?

Newsome: Actually, my next trip will be to Lisbon for the Champalimaud celebration, which I am very much looking forward to! It should be a great party.

Movshon: Lisbon will be a fine enough trip, thanks! And the climate is better than Stockholm's.

\section{Kathryn Claiborn}

